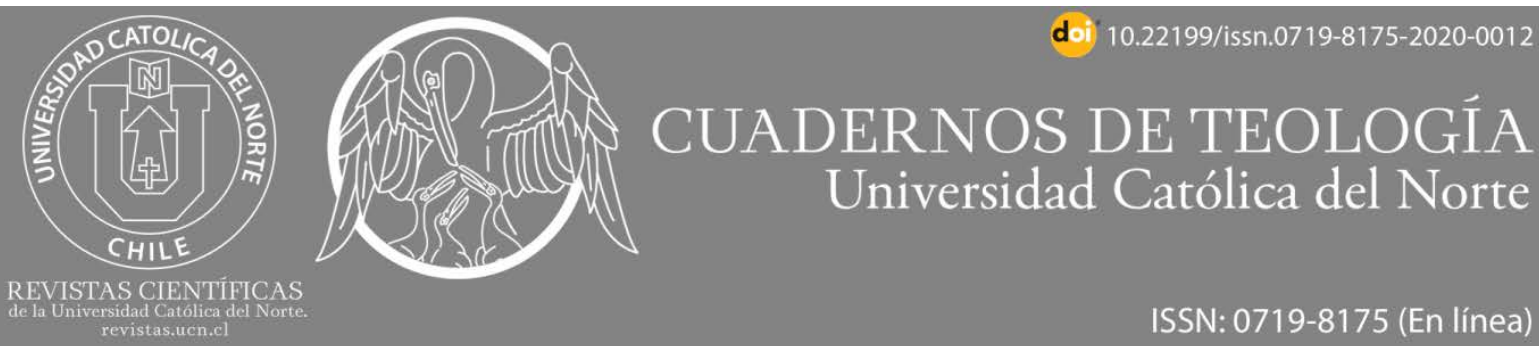

\title{
La conciencia de la presencia como clave para la renovación de la experiencia espiritual hoy: Gregorio de Nisa, Ignacio de Loyola, Teresa de Jesús, Laura Montoya, Etty Hillesum y Benjamín González Buelta
}

\section{Awareness of presence as a key to renewal of the spiritual experience today: Gregory of Nyssa, Ignatius of Loyola, Teresa of Jesus, Laura Montoya, Etty Hillesum, and Benjamín González Buelta}

\author{
Orlando Solano Pinzón' ${ }^{10}$ orcid.org/0000-0001-5047-857X \\ Rosana Navarro Sánchez ${ }^{2}$ 응 orcid.org/0000-0003-0322-669X \\ Jairo Gómez Díaz ${ }^{3}$ (D) orcid.org/0000-0001-7244-4354 \\ William Augusto Peña Esquivel ${ }^{4}$ (D) orcid.org/0000-0002-6193-8321 \\ Gabriel Alberto Jaramillo Vargas ${ }^{5}$ (D) orcid.org/0000-0002-8356-1094 \\ Pontificia Universidad Javeriana, Bogotá, Colombia. \\ 10.solano@javeriana.edu.co; ${ }^{2}$ rosana.navarro@javeriana.edu.co; ${ }^{4}$ penaw@javeriana.edu.co. \\ 50 gabrieljaramillo@javeriana.edu.co. \\ ${ }^{3}$ Universidad Pontificia Comillas, Madrid, España. \\ gomez.jairo@javeriana.edu.co. \\ (cc) BY
}

\section{Resumen:}

Debido a la crisis de las mediaciones tradicionales de la experiencia religiosa, asistimos a una búsqueda espiritual cada vez más generalizada, derivada de la tendencia a ultraindividualizar, con la pretensión de autorrealización. En respuesta a tal situación, este escrito recoge los resultados de una investigación que, con el trasfondo la intuición del futuro místico de la humanidad, se aproxima a la experiencia de seis testigos espirituales de ayer y de hoy. La aproximación indagó por los rasgos propios de la experiencia mística, comprendida como conciencia de presencia, para identificar claves capaces de contribuir a la renovación de la experiencia espiritual en la actualidad.

Palabras Clave: Experiencia mística; Oración; Autoconocimiento; Conciencia de presencia.

\section{Abstract:}

Due to the crisis of traditional mediations of religious experience, we are witnessing a more and more generalized spiritual search, derived from the tendency to ultra-individualism, with the aim of self-realization. In response to such a situation, this writing collects the results of an investigation that, with the background of the intuition of the mystical future of humanity, approaches the experience of six spiritual witnesses of yesterday and today: Gregory of Nyssa, Ignatius of Loyola, Teresa of Jesus, Etty Hillesum, Laura Montoya, and Benjamín González Buelta. The approa.ch investigated the characteristics of the mystical experience, understood as awareness of presence, to identify keys capable of contributing to the renewal of spiritual experience today.

Keywords: Mystical experience; Prayer; Self-knowledge; Awareness of presence.

Fecha de recepción: 09 de diciembre de 2020 | Fecha de aceptación: 23 de diciembre de 2020 


\section{Introducción}

Al finalizar el siglo XX, algunos autores habían llamado la atención sobre la situación de vaciamiento de la experiencia espiritual, fenómeno que venía generalizándose. Entre ellos, cabe mencionar al francés André Malraux (1901-1976), quien afirmó: "El hombre del siglo XXI será espiritual o no será" (Goettmann, 1987, p. 43). Posteriormente, Karl Rahner (1904-1984) hizo pública una frase, acuñada originalmente por el teólogo español Raimon Panikkar (1918-2010), con la cual aseveró: "El cristiano del futuro o será un místico, una persona que ha experimentado algo, o no será" (Rahner, 1969, p. 25). Por último, el también teólogo alemán Eugen Biser (1918-2014) habló de una globalizada crisis de la fe, caracterizada por exceder el ámbito religioso y hacer gala de un talante fundamentalmente derrotista, frente al cual urgía el avance del cristianismo hacia su futuro místico (Biser, 1994, p. 16).

Sin embargo, asistimos también al desarrollo en Occidente de una verdadera búsqueda espiritual, que deriva de una tendencia a ultraindividualizar lo religioso y del deseo de autonomía de los seres humanos (Lenoir, 2003, pp. 50-51). La búsqueda de la felicidad, la autorrealización y el culto a la autenticidad aparecen como características de un individualismo exacerbado. La libertad individual se emancipó radicalmente de cualquier imagen jerárquica que quisiera establecer un orden o un modelo de humanidad (Taylor, 2008, pp. 9-11). Charles Taylor aborda la problemática del individualismo moderno, catalogado como la más bella conquista de la modernidad. Sin embargo, esta conquista no deja de generar un malestar en la sociedad. El análisis de Taylor permite identificar sus efectos en la compresión de lo religioso y lo espiritual en el mundo de hoy.

De acuerdo con lo anterior, el presente escrito recoge parte de los resultados de una investigación cuyo trasfondo es el pensamiento de los autores mencionados y está motivada por el estado de crisis de las mediaciones tradicionales de la experiencia espiritual. El trabajo busca aproximarse a dicha experiencia, en particular, la vivida por seis testigos espirituales de ayer y de hoy. En dicha aproximación, se indagó sobre los rasgos propios de la experiencia mística, comprendida como conciencia de presencia, con el ánimo de identificar insumos capaces de contribuir a la renovación de la experiencia espiritual en la actualidad.

En este orden de ideas, el itinerario propuesto parte de un acercamiento al concepto de conciencia de presencia. Luego, se presenta la comprensión de cada uno de los autores estudiados en cuanto a esta categoría. Al final, se dan a conocer algunas implicaciones de la comprensión de aquella categoría como insumo para la vida espiritual contemporánea.

\section{La conciencia de presencia}

El ser humano es plenamente ser humano

si hace la experiencia de lo divino; si no, no llega todavía a integrarse en lo humano.

Panikkar 
Para adentrarnos en la conciencia de la presencia divina, es importante realizar un breve acercamiento a la comprensión de los conceptos de experiencia, experiencia espiritual y experiencia religiosa, sin pretender ahondar en este tema ampliamente investigado. Comprendemos que la experiencia es "una forma de conocimiento y aproximación a la realidad", en la cual, "a partir de un 'salir de sí, como apertura, encuentro y relación con el ser, se conjugan la intuición y el pensamiento hacia una progresiva autoconciencia, autoconocimiento y construcción plena del ser humano como ser en relación" (Navarro Sánchez, 2017, p. 47).

Por su parte, la experiencia espiritual consiste en la conciencia de aquella búsqueda fundamental, instalada en lo humano. Cuando tal experiencia se abre a lo sagrado, tiene lugar la experiencia religiosa, que se convierte en experiencia mística cuando acontece el "encuentro con Dios en lo profundo del corazón, que supone una existencia que camina hacia lo profundo, sin enajenarse, en conciencia plena de la realidad" (Navarro Sánchez, 2017, p. 49). Se trata de una experiencia de la presencia divina, que hace renacer al ser humano, en una comunicación interpersonal que lo transforma, para que descubra progresivamente dicha presencia y se logre la igualdad en el amor, de manera que la persona experimenta, pasivamente, el don de Dios en su más profundo centro; mientras se pone, activamente, en tensión para servir y cuidar a los otros y a la creación en sí misma.

En este sentido, la conciencia de presencia es la conciencia de la relación en la que, en términos buberianos, el tú eterno se me pone enfrente y el yo se pone en relación inmediata respecto a él. De este modo, la relación es pasión y acción al mismo tiempo y, "el ser humano todo, ceñido en su totalidad, descansando en su totalidad, actúa" (Buber, 2017, p. 70), es decir, se vuelve un ser actuante. En efecto, la conciencia de presencia mantiene un equilibrio entre la interioridad y la exterioridad, en tanto el amor catapulta al ser humano fuera de sí mismo y le hace descubrir el tú auténtico del mundo que le rodea. En la conciencia de presencia no se descubre un otro fuera de sí (este lo encuentra el intelecto), sino un tú fundado en el amor mismo.

Si bien la categoría conciencia de presencia no es explícita en todos los autores estudiados, es posible observar, a través de su experiencia y sus escritos, cómo cada uno hace evidente la consciencia de presencia que es también conciencia de sí y del mundo particular que vivieron.

\section{La conciencia de presencia en el itinerario espiritual de seis personajes de ayer y de hoy}

\subsection{El camino espiritual de Gregorio de Nisa}

Gregorio de Nisa (ca. 335-394) es un Padre de la Iglesia, conocido como uno de los tres capadocios, junto con Basilio de Cesarea (ca. 330-379) y Gregorio de Nacianzo (ca. 329389). Nació en Capadocia (Maraval, 2006), en una familia numerosa, marcada con el sello de la santidad. Su abuela Macrina recibió la fe por medio de San Gregorio Taumaturgo (ca. 213270), quien, a su vez, fue discípulo del gran maestro Orígenes de Alejandría (ca. 185-254). 
Basilio y Emelia, sus padres, provenían de familias cristianas prestantes, que sufrieron persecución a causa de su fe, por lo cual estaban dispuestos, como los mártires de los primeros siglos, a perder su propia vida, emigrar y renunciar a sus riquezas.

$\mathrm{Su}$ itinerario espiritual estuvo influido fuertemente por su familia, en la cual aprendió no solo la santidad, sino también un tipo de vida célibe, con una fuerte inclinación monacal. A pesar de estar encaminado hacia el sacerdocio, Gregorio experimentó un momento de crisis personal, que lo llevó a abandonar su vocación y seguir la carrera retórica como su padre. En ese periodo, se distanció de la vida contemplativa que llevaba y, al poco tiempo, contrajo matrimonio, pero su experiencia matrimonial fue traumática $y$, al parecer, su esposa falleció en su primer parto (Silvas, 2007, p. 25).

Luego de aquella experiencia, nuestro santo retomó su vida contemplativa, recibió el sacerdocio y, en medio de las confrontaciones con los arrianos, fue consagrado obispo de Nisa por su hermano Basilio. Después de la muerte de este último, Gregorio desempeñó un papel determinante en el Concilio de Constantinopla. Su liderazgo se hizo más notable en la defensa de la fe de Nicea, hasta el punto de que llegó a ser considerado uno de los guardianes de la ortodoxia.

Así como en sus hermanos, su espiritualidad estaba intrínsecamente unida a la misericordia con el prójimo, en especial, con los más sufrientes, los pobres y los leprosos, de modo que buscaba combatir la injusticia social, en especial, la de quienes padecían "la enfermedad de la avaricia" (De Nisa, 1988, p. 81). Junto con la defensa de la fe y el celo pastoral por los más necesitados, Gregorio estuvo comprometido también con la guía espiritual de las almas, como puede verse en los textos que escribió para orientar la vida espiritual de los monjes y sus fieles.

Su influencia espiritual fue reconocida después por Jorge de Pisidia (580-634), en el siglo VII, cuando fue llamado el más místico de todos los místicos ( 1863, p. 46). Posteriormente, a mediados del siglo XX, Daniélou (1944, p. 7), lo consideró como el fundador de la teología mística.

\subsubsection{La conciencia de presencia en Gregorio de Nisa}

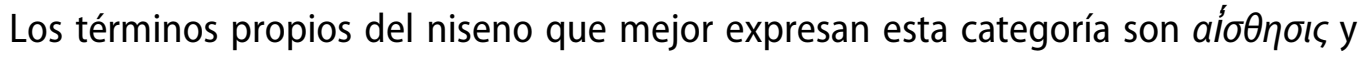

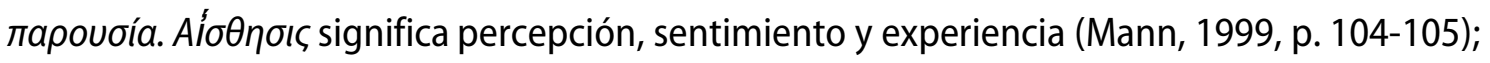
mientras que rapouбía hace referencia a una presencia que es manifestación de Dios (Mann \& Drecoll, 2009, p. 179-181). De esta manera, la conciencia de presencia en Gregorio es la

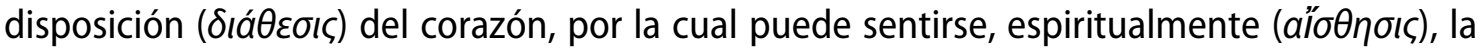
presencia (лароибі́a) de Dios, por medio de una relación (бхв́бı) personal de intimidad con

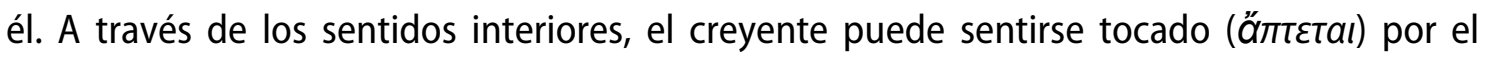
misterio y reconocer en su propia identidad de hijo de Dios a aquel que quiso habitar

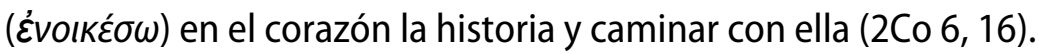

Esta conceptualización se explicita por medio de un par de pasajes de las Homilías sobre el Cantar de los cantares, en los que el obispo de Nisa expresa estas categorías. El primer texto es tomado de su exégesis sobre el versículo siete del primer capítulo del Cantar 
(Ct 1,7), en el que la esposa está buscando al esposo y lo invoca como el amado de su alma. De Nisa (2015) lo expresa de la siguiente manera:

Para designar el objeto de sus deseos, emplea los términos que corresponden a los sentimientos verdaderamente enraizados en ella y que por él experimenta (...). En toda la tierra no hay quien pueda expresarlo ni aun pensarlo. El único término apropiado para designarte a ti y tu bondad es el sentimiento que anima mi alma en

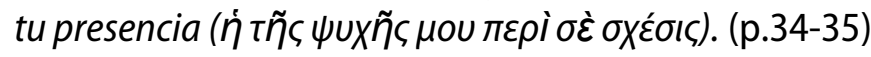

Gregorio evidencia que todo nombre atribuido a Dios es insuficiente para expresar

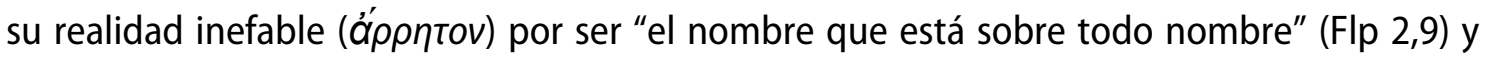
como tal, no puede ser encerrado en conceptos. Lo único que puede afirmar de Dios con propiedad es el sentimiento interno de su presencia, sentida en proporción a la disposición

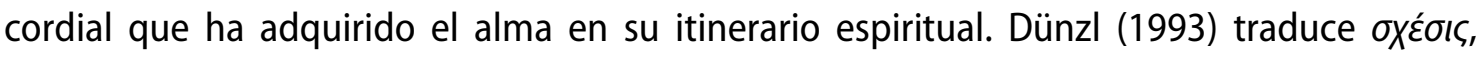
como el amor del alma que "está en disposición hacia él" (p.73), lo cual resulta interesante, en cuanto oxźoıৎ indica una disposición relacional (Vigorelli, 2014, pp. 277-300), cuyo fundamento es el amor.

La conciencia de presencia es la afirmación humilde del apofatismo de Gregorio, en el que declara que el misterio de Dios es inefable y está envuelto en la oscuridad de la tiniebla (үvó inflamado en amor, como puede verse en este otro pasaje del obispo (De Nisa, 2015):

Miradla ahora envuelta en noche divina: el esposo está con ella, pero no se deja ver. ¿Por qué no se le ve de cerca en la noche? No obstante, él da al alma cierta señal

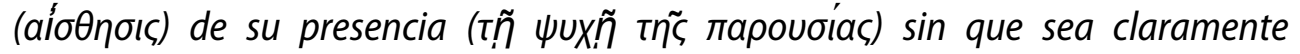

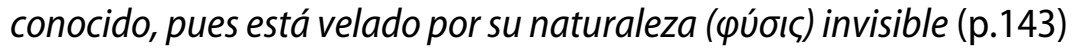

La esposa está acostada en su cuarto y escucha la voz del amado en la puerta, que la llama. Sin embargo, cuando le abre, ya no está. Esto produce en su alma una herida de amor por su ausencia (Ct 5,2-7). En esta herida, el esposo da al alma una conciencia de su presencia, tan clara, que hasta siente cómo la mano toca la cerradura de la puerta y la deja untada de mirra. Dicho sentimiento la enciende en deseos de salir a buscar al amado, con lo cual se da a entender que el grado más alto de la mística consiste en seguir a Cristo. Lo más cierto que puede tener un alma dispuesta para el encuentro con Dios es la conciencia interior de su presencia, que la toca y la mueve al seguimiento de Cristo, en la historia. En este sentido, el sentimiento de la presencia se convierte en una mística del seguimiento de Cristo, desde un corazón apasionado.

\subsection{El recorrido interior Ignacio de Loyola}

Conocido originalmente como Íñigo López, San Ignacio de Loyola nació en 1491 en la casa solariega de su familia en el País Vasco. En cuanto a su vida familiar, fue el menor de trece hermanos (Cándido De Dalmases (1986), considera que no es posible llegar a conclusiones definitivas sobre el número de hermanos de Ignacio, puesto que dos de ellos fueron ilegítimos y se presume la existencia de otra hermana de la que no hay evidencia clara), vivió la orfandad de su madre desde muy temprana edad y, teniendo 15 años, fue enviado a la Corte de Arévalo, al servicio de Juan Velásquez de Cuéllar, el contador mayor 
del Reino, donde se formó como cortesano (De Loyola, 1990, p.1). Con el despido de Velázquez de Cuéllar de sus funciones, pasó a ser parte de la Corte de Nájera, donde se dedicó a un servicio cortesano distinto, que le obligó a mediar en conflictos entre familias de esa región y participar en empresas militares.

Por ese motivo, en mayo de 1521 llegó a Pamplona, España, para defender a la Corona de Castilla del ataque francés. Protegiendo el fuerte militar de la ciudad, "le acertó a él una bombarda en una pierna, quebrándosela toda; y porque la pelota pasó por entrambas las piernas, también la otra fue mal herida" (De Loyola, 1990, p.1). En pobre condición de salud, fue conducido por soldados franceses a su casa, donde empezó a recorrer un camino interior que lo conduciría a ofrecer totalmente su vida al servicio de Dios. Mientras se recuperaba, llegó a ser consciente de los pensamientos que le sobrevenían y de lo que le dejaban.

Terminada su convalecencia, Ignacio planeó una nueva orientación para su vida. Pensó, por un momento, ingresar a la Cartuja en Sevilla, pero optó por ir como peregrino a Jerusalén, buscando una experiencia más intensa con la persona de Jesús. Después de algunos meses, logró embarcarse hacia Tierra Santa, pero, al no poder permanecer allí, debido a la guerra contra los turcos en el Mediterráneo, debió regresar a su patria. Por su deseo de ayudar a los demás, acrecentado por experiencia personal, le aconsejaron estudiar latín en la Universidad de Barcelona, como en efecto ocurrió.

Posteriormente, continuó sus estudios en Alcalá de Henares, aunque no avanzó prácticamente nada, porque bien se dedicó más al acompañamiento espiritual, o bien porque la Inquisición comenzó a sospechar de sus conversaciones y doctrina espiritual. Esto lo llevó a Salamanca, donde fue procesado por estar instruyendo a otros en cosas de Dios, sin la preparación académica requerida. Por este motivo, se vio obligado a viajar a París, donde terminó sus estudios y conoció a Francisco Javier, Diego Laínez, Alfonso Salmerón, Pedro Fabro, Nicolás Bobadilla y Simón Rodríguez, sus primeros compañeros. Todos ellos, amigos en el Señor, consagraron sus vidas a Dios haciendo votos de pobreza, castidad, vida apostólica y peregrinación a Jerusalén, en Montmartre. Con ellos decidió ir a presentarse ante el papa, para que los empleara donde hubiera mayor necesidad de su trabajo, de acuerdo con el criterio papal (De Loyola, 1990, p. 96).

Una vez en Roma, en la cuaresma de 1538, los compañeros encontraron que la constitución de una Orden es de Dios. Aquella fue aprobada formalmente en 1540 por el papa Paulo III. Ignacio fue elegido superior general, en 1541, año en el que también los primeros compañeros hicieron sus últimos votos en la basílica de San Pablo Extramuros. Luego de un generalato de 16 años, el 31 de julio de 1556, murió Ignacio de Loyola.

\subsubsection{La conciencia de presencia de Ignacio de Loyola}

En el Santo de Loyola, la toma de conciencia de la presencia del misterio de Dios es progresiva. Para él, "Dios habita en las criaturas, en los elementos, dando ser; en las plantas, vegetando; en los animales, censando; en los hombres, dando entender" (De Loyola, 1970, p. 235). En este sentido, el ser humano está llamado a la vida por él, con él y en él, haciéndose disponible a la voluntad del Padre, como Jesús, que es la acción con la cual el hombre lleva a la plenitud la filiación a la cual ha sido llamado: 
Principio y fundamento: el hombre es criado para alabar, hacer reverencia y servir a Dios nuestro Señor y, mediante esto, salvar su ánima; y las otras cosas sobre la haz de la tierra son criadas para el hombre y para que le ayuden en la prosecución del fin para que es criado. De donde se sigue, que el hombre tanto ha de usar dellas, quanto le ayudan para su fin, y tanto debe quitarse dellas, quanto para ello le impidenen. (De Loyola, 1970, p. 235).

Ahora bien, si la presencia de Dios en toda la creación es clara, conviene señalar que, para Ignacio, dicha presencia no es estática sino dinámica, en tanto que "Dios trabaja y labora por mí en todas las cosas creadas sobre la haz de la tierra" (De Loyola, 1970, p. 236). Este trabajo y esta labor de Dios por cada persona es un don gratuito que, una vez experimentado, la mueve a poner a su disposición la voluntad y la vida propias.

Esta propuesta espiritual, tiene la convicción de la posibilidad de buscar y hallar a Dios en todas las cosas, lo cual implica un proceso de crecimiento (De Loyola, 1990, p. 99). Dios, por su parte, tiene una pedagogía con cada persona para hacerse comprensible -"En este tiempo le trataba Dios de la misma manera que trata un maestro de escuela a un niño, enseñándole" (De Loyola, 1990, p. 27)-, con un lenguaje mediador del encuentro que, como todo lenguaje, debe ser descubierto y aprendido por el hombre para ser capaz de reconocer y escuchar la voz del Espíritu Santo desde la base del discernimiento y así poder responder a sus llamados. Su experiencia de convalecencia (De Loyola, 1990, p. 8) y lo que vivió en el Cardoner (De Loyola, 1990, p. 30) dan testimonio sobre este particular.

Desde esta experiencia de Ignacio, es posible afirmar, con Melloni Ribas (2001), que visión y conocimiento van muy ligados en la experiencia mística (p. 46). La visión nueva de la realidad en clave contemplativa transforma la vida desde una perspectiva holística. La novedad que aporta esta nueva mirada en el trato con Dios es el sentirse volcado al mundo, a las realidades concretas; es hacer experiencia del amor recibido de Dios -En palabras de San Juan: "Nosotros amamos, porque él nos amó primero" (1Jn 4,19) - y comunicarlo en el modo del servicio. En palabras del mismo Ignacio: "Gastar la vida en provecho de las almas" (De Loyola, 1990, p. 85). Así, el encuentro con Dios impulsa siempre a dar respuesta, a comunicar la propia experiencia (De Loyola, 1970, p. 230). Es más, la toma de conciencia de la presencia de Dios se expresa en el deseo y petición continua (De Loyola, 1990, p. 96), de ser puestos con el Hijo para vivir con él, por él y en él, tal como puede constatarse en la experiencia de La Storta:

Estando un día, algunas millas antes de llegar a Roma, en una iglesia, y haciendo oración, sintió tal mutación en su alma y vio tan claramente que Dios Padre le ponía con Cristo, que no tendría ánimo para dudar de esto, sino que Dios Padre le ponía con su Hijo. (De Loyola, 1990, p. 96)

A manera de conclusión, en la mística que Ignacio vivió, según Rambla, se encuentran "hermanadas la unión con Cristo (el amor) y la claridad interior (el discernimiento), [pues] la claridad que ayuda a discernir no es la que proviene de ideas o criterios y normas generales y frías, sino la que nace de la relación con Cristo" (De Loyola, 1990, p. 96).

Es el discernimiento, animado por la fe, el modo por el cual Ignacio de Loyola hizo conciencia de la presencia de Dios en él, los otros y el mundo. El peregrino comprendió que 
los fenómenos que experimentaba eran tan diversos como sus causas. Estas, tan diversas y contradictorias como él las descubría en su interioridad, lo llevaron a distinguir lo propio de Dios y saber cuándo estaba presente y cuándo no. Aunque era amigo de empezar todo por la experiencia personal o la de quienes recibieron su compañía, no se detenía en lo empírico, sino que pasaba a lo sistemático; de la anécdota, a la categoría; de la descripción, a la definición. Las experiencias de Loyola y Manresa dieron como resultado sus Ejercicios espirituales cuya motivación era buscar a Dios y hallarlo (De Loyola, 1990, p. 329-331).

\subsection{La unión espiritual de Teresa de Jesús}

Teresa de Jesús, "la fémina inquieta, andariega, contumaz y desobediente"1, nació en Ávila, España, el 28 de marzo de 1515. En su adolescencia ingresó como estudiante al convento de Agustinas de Nuestra Señora de Gracia de Ávila (1531). Sin estar convencida de su vocación religiosa, se incorporó al Monasterio Carmelita de La Encarnación de Ávila, el 2 de noviembre de 1535. Allí vivió una vida de oración, con la cual descubrió la riqueza del gran "mundo interior". Junto a algunas mujeres amigas y con el apoyo de algunos confesores y familiares decidió fundar el Monasterio de San José de Ávila.

Teresa es reconocida por sus grandes escritos espirituales: Vida, Camino de perfección, Las moradas o Castillo interior, Fundaciones y Cuentas de conciencia, entre otras. En su obra, ofrece uno de los grandes aportes a la espiritualidad universal: la experiencia mística en la que se descubre la profundidad del alma humana, en cuyo centro acontece la unión con Dios, expresada como matrimonio espiritual. La reformadora de los carmelitas murió el 15 de octubre de 1582, fue beatificada en 1614, canonizada en 1622 y declarada Doctora de la Iglesia en 1970.

\subsubsection{La conciencia de presencia en Teresa de Jesús}

Cuando hablamos de conciencia de presencia, es decir, la presencia divina, en la experiencia de Teresa de Jesús nos referimos a la comunicación de Dios a la persona humana, como una realidad dinámica, que obra y es tanto la raíz como la fuerza de su espiritualidad. La presencia divina es Dios mismo, que se pone en contacto personalmente con el ser humano. En la Doctora de la Iglesia, la toma de conciencia de la presencia divina es un proceso de interiorización (García Ordas, 2011). Así, la vida espiritual es la progresiva toma de conciencia de la presencia divina que habita en el "centro del alma" y se realiza de manera particular en el camino de la oración, entendida como el trato de amistad con Dios (De Ávila, 1967, p. 50).

La primera realidad que ella descubrió como fundamento de su vida espiritual fue la persona de Cristo. Su búsqueda inicial se realizó por medio de la lectura. Ese descubrimiento de los libros se concretó, paulatinamente, en la relación personal con su amigo, señor y esposo. Al inicio de la vida de oración, como medio donde se revela y experimenta la presencia de Dios, la persona está llamada a "pedir y considerar estar en su presencia" (De Ávila, 1967, p. 389). Los libros y las imágenes le fueron de gran ayuda para poder meditar y representar a Cristo en su interior. Luego, comprendió que la mejor manera de entrar en

\footnotetext{
${ }^{1}$ Expresión de Fillipo Sega (1537-1596), nuncio papal en España.
} 
contacto con Cristo era mirarlo, hablarle y dejarlo entrar en la vida ordinaria (De Ávila, 1967, p. 243-245). De ese modo, la presencia de Cristo se manifiesta exteriormente y Teresa lo expresa así: "Junto con Cristo", "cabe ${ }^{2}$ Cristo". En definitiva, esta presencia exterior, por yuxtaposición, se interioriza y se injerta en su vida: "por presencia, potencia y esencia" (De Ávila, 1967, p. 394).

Teresa experimenta que Dios está presente en todas las cosas, una presencia real de Dios en ella y en todo, no solo intencionalmente, por gracia, sino que Dios está en lo más íntimo del ser de cada persona: "Es de considerar aquí que la fuente y aquel sol resplandeciente que está en el centro del alma no pierde su resplandor y hermosura, que siempre está dentro de ella y cosa no puede quitar su hermosura" (De Ávila, 1967, p. 368).

Otra experiencia más profunda de la presencia de Dios tiene que ver con lo que acontece en la unión espiritual, que trae un particular conocimiento de Dios, toda vez que produce un amor muy tierno y deseo de servirle, con una mayor conciencia de la presencia divina que la habita (De Ávila, 1967, p. 427-428). Esta presencia actúa en el interior del alma, donde genera un cambio radical. La persona debe dejarse encontrar por tal presencia. Ello debe agradarle y, sin olvidar la meditación en la vida de Cristo, debe:

... no se apartar de andar con Cristo nuestro Señor, por una manera admirable, adonde divino y humano junto es siempre su compañía. Así que, cuando no hay encendido el fuego que queda dicho en la voluntad ni se siente la presencia de Dios, es menester que la busquemos; que esto quiere Su Majestad, como lo hacía la esposa en los Cantares, y que preguntemos a las criaturas quién las hizo (como dice San Agustín, creo, en sus Meditaciones o Confesiones), y no nos estemos bobos perdiendo tiempo por esperar lo que una vez se nos dio, que a los principios podrá ser que no lo dé el Señor en un año, y aun en muchos; Su Majestad sabe el porqué; nosotras no hemos de querer saberlo, ni hay para qué. Pues sabemos el camino como hemos de contentar a Dios por los mandamientos y consejos, en esto andemos muy diligentes, y en pensar su vida y muerte, y lo mucho que le debemos; lo demás venga cuando el Señor quisiere. (De Ávila, 1967, p. 425)

En la unión del matrimonio espiritual, la experiencia de la presencia divina va acompañada por diversas gracias espirituales: visiones, arrobamientos, purificaciones, locuciones interiores (hablas divinas), conocimiento por amor (iluminaciones). Estas gracias especiales revelan, progresivamente, la presencia divina, hasta el punto de que se experimenta de forma permanente en la vida de la persona, ya no solo la presencia de Cristo, sino la de la Trinidad misma (De Ávila, 1967, 439-440).

Para concluir esta sección, podemos decir que la experiencia espiritual teresiana gira en torno a la presencia de Cristo. Se trata de un progreso definido con claridad, desde la experiencia de una presencia exterior, "cabe vos", una compañía de Cristo de forma exterior a la persona, por yuxtaposición (De Ávila, 1967, p. 243-245), hasta la experiencia interior de dicha presencia, una "presencia de interiorización", Cristo injertado en su vida interior. La experiencia con Cristo como maestro, que enseña a discernir y vivir la vocación y revela, progresivamente, su presencia, se observa en Teresa por medio de las enseñanzas de la

\footnotetext{
${ }^{2}$ Es decir, "junto a".
} 
palabra de Dios en la Escritura, por las palabras del mismo Cristo, a quien escucha en su interior, y por la misma vida, contemplada a la luz de la fe (Castellano, 2014, p. 186-189). Se trata de una experiencia de transformación, de conversión a Dios, marcada por diferentes momentos cristológicos que gradualmente vivió: Dios a "nuestro lado" (De Ávila, 1967, p. 118), Dios "dentro de nosotros" (De Ávila, 1967, p. 471) y nosotros "dentro de Dios" (Marcos, 2015).

Esa experiencia de transformación tiene su punto de apoyo en el amor divino y en la libertad que se genera como fruto de la conversión: "Sea Dios bendito por siempre, que en un punto me dio la libertad que yo (...) no pude alcanzar conmigo" (De Ávila, 1967, p. 118). El resultado es la transformación de la psique humana, pues el entendimiento queda trascendido, la memoria se purifica y la voluntad queda ocupada solo en amar (Marcos, 2015, p. 192-193). De manera que el amor de Dios, concretado en la persona de Cristo, es la verdadera fuente de la libertad.

En resumen, puede afirmarse que la vocación de Teresa es una constante relación con la presencia divina, que puede llamarse comunicación personal que, de manera dinámica y transformante, se desarrolla en una permanente confrontación. Esa presencia entra en contacto con la persona humana, actuando por medio de comunicaciones de amor y de conocimiento, que generan una transformación integral.

\subsection{El quebrantamiento personal de Etty Hillesum}

Esther Hillesum, conocida con el diminutivo Etty, nació en Middelburg, Holanda, el 15 de enero de 1914. Louis y Riva, sus padres, eran judíos; y tuvo dos hermanos: Jaap, que era médico, y Mischa, que fue pianista.

Durante su vida, Hillesum experimentó el quebrantamiento de su ser personal y la ausencia de asideros y referentes fundantes. A ello se suman la profundidad de sus emociones, la búsqueda de nuevas experiencias afectivo-sexuales y la despreocupación por referentes normativos morales, entre otros. Más aún, la acompañaba su facilidad tanto para ver la realidad en sus detalles, como para integrar y articular sus experiencias. Poseía gran capacidad de observar, escuchar, sentir y dejarse impregnar por la realidad.

Estudió derecho, lenguas eslavas y se encontraba estudiando psicología cuando los ejércitos alemanes invadieron Holanda, durante la Segunda Guerra Mundial. De Etty, nos quedan su Diario y sus Cartas, en los que se evidencia que escribir y narrarse fueron la clave para resolver su existencia, en profundo caos interior. Esta iniciativa de escribir fue una invitación Julius Spier, su mentor y "partero de su alma" como ella misma lo llamaba.

El ocho de marzo de 1941, con el influjo y la orientación de Spier, Etty emprendió la escritura de su Diario. La última página conocida de esta labor corresponde a un año y medio después, el 13 de octubre de 1942. De sus Cartas, tenemos noticia hasta el siete de septiembre de 1943, día en que escribió una postal desde el tren en que era deportada, con 
su familia, a Auschwitz (Hillesum, 2002, p. 658-659) ${ }^{3}$. Su muerte quedó registrada el 30 de noviembre de 1943.

\subsubsection{La conciencia de presencia o el emerger de la vida hacia y desde las profundidades}

Al pretender reconocer y describir el proceso y los rasgos propios de lo que denominamos conciencia de presencia en la experiencia de Etty Hillesum, luego de un acercamiento al relato de su Diario y de algunas de sus Cartas, es posible identificar categorías como escucha, interioridad y oración.

El proceso espiritual de Hillesum surgió como consecuencia del momento en que se encontraba a sus veintisiete años. Se planteaba preguntas en medio de un momento crítico de insatisfacción y confusión, que expresaba con palabras como mi "caos interior" (Hillesum, 2002, p. 6) o "mi constipación espiritual" (Hillesum, 2002, p. 6). Cuando Spier apareció en su vida, comenzó el desafío de convertir en narración lo que acontecía en su interior. De ese modo, comenzaron a hacerse explícitas sus preguntas existenciales, junto con el ferviente deseo de resolverlas.

Acompañada de autores de su predilección, como Rilke, San Agustín o Dostoievski, y sus libros preferidos, como la Biblia, junto con su constante diálogo con las realidades exterior e interior, Hillesum vivió una evolución de su pensar, su sentir y del proceso de experimentar aquella presencia que la animaba y acompañaba desde el fondo de su ser: "Hay un pozo muy profundo dentro de mí. Y en él habita Dios. A veces yo también estoy allí. Pero más a menudo las piedras y la arena bloquean el pozo, y Dios está enterrado en lo profundo. Entonces debe ser desenterrado nuevamente" (Hillesum, 2002, p. 91).

Etty decidió "escuchar su voz interior". Al parecer, lo logró con cierta rapidez (tal vez se trataba de un don natural), de modo que pronto logró sumergirse en ese mundo interior que le prodigaba paz y que, según ella, se asemejaba a un paisaje con llanuras inmensas, un paisaje de "espacios sin límites":

Creo que lo haré de todos modos: 'Me volveré hacia adentro' durante media hora cada mañana antes del trabajo y escucharé mi voz interior (...). Una media hora dentro de ti misma. No es suficiente mover las piernas y los brazos y todos los demás músculos en el baño cada mañana. El ser humano es cuerpo y espíritu. $Y$ media hora de ejercicios combinados con media hora de meditación pueden establecer el tono durante todo el día. (Hillesum, 2002, p. 56)

Etty reconoce la importancia de este ejercicio: "Lo que hago es hineinhorchen (escuchar) (me parece que esta palabra es imposible de traducir). Escucharme a mí misma, a los demás, al mundo. Escucho muy atentamente, con todo mi ser, e intento comprender el significado de las cosas" (Hillesum, 2002, p. 90-91). Luego de la muerte de Spier, ya fortalecida y desde una nueva toma de conciencia, escribió, muy convencida:

\footnotetext{
${ }^{3}$ La postal iba dirigida a Christine van Nooten. Etty la lanzó por la rendija del tren que la conduciría al campo de concentración de Auschwitz, el martes siete de septiembre de 1943.
} 
Verdaderamente, mi vida es una larga escucha de mí misma y de los demás, de Dios. Y si digo que escucho, es realmente Dios quien escucha dentro de mí. Lo más esencial y lo más profundo de mí escuchando lo más esencial y profundo del otro. Dios a Dios 'Qué grandes son las necesidades de tus criaturas en esta tierra, oh, Dios'. (Hillesum, 2002, p. 519)

Hillesum logró convertir su existencia en escucha, atenta y permanente, de su interior, de los otros y de la vida misma. Todo en permanente diálogo y armonía, incluso en medio de la realidad de muerte y destrucción propia de la guerra. Junto a aquella escucha, la interioridad desempeña un papel central en su vida:

El mundo interior es un terreno en barbecho, no cultivado, que no parece valer la pena. Es tierra desconocida. $Y$, a veces, siento la necesidad de comenzar el trabajo de recuperación, de crear orden y de traerlo a la conciencia. Quién sabe, a la larga ese puede ser el trabajo de mi vida. (Hillesum, 2002, p. 60).

Interioridad y exterioridad llevan una articulación perfecta, pues la una no se concibe sin la otra. Esto excluye cualquier sospecha de intimismo en el proceso de conquistar su propia interioridad. Etty nos deja unas claves para cultivar esa vida interior: "No debes concentrar tus fuerzas internas en una sola cosa, no debes invertirlas en ellas, debes mantener tus fuerzas para ti misma. Y eso es suficiente sabiduría por el momento" (Hillesum, 2002, p. 67).

La sencillez es parte de la ganancia del proceso espiritual orientado a la conciencia de presencia. No hay posibilidad de ganar en conciencia interior y exterior sin renunciar ni volver a la fuente simple de la vida; la atención en lo central es el único modo de encontrar sentido. Así, el campo de concentración se convirtió para ella en una posibilidad de experiencia interior: "En Westerbork fue como si estuviera frente a la empalizada desnuda de la vida. El marco más interno de la vida, despojada de todas las trampas externas. Gracias, Dios, por enseñarme a leer mejor y mejor" (Hillesum, 2002, p. 522). Así pues, el camino interior es maestro de lectura de la vida para Etty Hillesum. Mayor conciencia de presencia en medio de las más difíciles condiciones exteriores.

Además de la escucha y la interioridad, la experiencia de oración también contribuyó a su progresiva conciencia de presencia. En su relación con Dios, pueden identificarse tres momentos: el primero, la simple alusión inicial en su diario, como a un tercero al que se acude de manera despreocupada; el segundo, cuando se dirige a él con cierto énfasis en la oración de petición: "Oh Dios, tómame en tus grandes manos y conviérteme en tu instrumento, déjame escribir" (Hillesum, 2002, p. 68); el tercero y definitivo ocurre cuando su oración se convierte en un diálogo ininterrumpido con Dios:

Dios mío: mi existencia es un diálogo incesante contigo. Probablemente no llegue a ser la artista en la que quisiera convertirme, pero al menos vivo dentro de ti. Me gustaría concebir aforismos y relatos vibrantes; sin embargo, la primera y última palabra que acometo es invariablemente la misma: Dios. Y eso lo abarca todo y desecha lo fútil, y mi energía creadora se agota en diálogos interiores contigo. Mi latido se ha ensanchado desde que estoy aquí, más animada a la par que tranquila, y ello me troquela con la convicción de que mi riqueza humana aumenta. (Hillesum, 2002, p. 640) 
Desde el caso de esta mujer, es posible confirmar la correlación entre el contexto histórico-cultural y el modo de acontecer de la experiencia mística. Para Etty Hillesum, la conciencia de presencia fue un proceso que implicó hacer frente a su caos interior, su situación familiar y la complicada realidad de su tiempo. También implicó que experimentara la necesidad del silencio, la escucha y la creación de una "disciplina de vida" que la condujo, progresivamente, a vivir la experiencia de la presencia, del tú, eso otro de sí, en su interior. Experiencia que se hace presencia, conciencia, lucidez, amor a la humanidad y deseo irrefrenable de darse y encontrar al Dios escondido en el otro.

\subsection{El fervor espiritual de Laura Montoya}

María Laura de Jesús Montoya Upegui nació el 26 de mayo de 1874, en Jericó, Antioquia, Colombia. Su infancia estuvo marcada por una serie de desavenencias económicas y familiares que la condujeron a una formación como maestra en la Escuela Normal de Institutoras de Medellín. En 1893, se graduó como maestra elemental de la Escuela Normal. Sus aspiraciones religiosas se manifestaron desde su juventud. Sin embargo, su deseo de hacerse religiosa carmelita descalza se vio frustrado por diversas circunstancias.

Durante su experiencia como maestra, Laura Montoya se destacó por su fervor y sus metodologías para enseñar la fe. A los 39 años, con la aprobación de monseñor Maximiliano Crespo, obispo de Santa Fe de Antioquia, decidió trasladarse a Dabeiba, junto con seis mujeres catequistas, para emprender lo que ella consideraba su verdadera vocación: evangelizar a las comunidades indígenas.

Laura Montoya escribió más de 30 libros, en los cuales consignó sus experiencias. Su obra más importante es Historia de las misericordias de Dios en un alma, donde relata su vida. Falleció en Medellín el 21 de octubre de 1949. En la actualidad, su Congregación de las Misioneras de María Inmaculada y Santa Catalina de Siena está presente en veintiún países y su trabajo consiste en acompañar a las naciones indígenas, los afrodescendientes y los campesinos.

\subsubsection{La conciencia de presencia en Laura Montoya}

Esta categoría es explícita en la obra de Laura Montoya. En su autobiografía, narra los acontecimientos de su vida, a la luz de la conciencia de su relación con Dios y del actuar divino en los trazos de su historia. Al comienzo de su Diario, la santa colombiana se pregunta por el inicio de esa conciencia:

¿Qué había de ser el dolor en un corazón de cuatro años sino una noche sin estrellas? ¿Cuándo tuve la primera idea de Dios? No lo recuerdo con precisión. Solo me doy cuenta de que fue más tarde. Sí puedo asegurar que estos primeros años, es decir, cuando pude advertir que existía, fueron una serie de lecciones de excepcional dureza. Ya provenían de la pobreza; ya del desprecio que en algunos miembros de la familia veía hacia mi madre, ya de la poca simpatía que a mi alrededor veía. (Montoya, 2017, p. 32). 
La idea de la divinidad expresada por Laura Montoya se refiere a la conciencia de la acción de Dios en su vida. Sin embargo, expresa que la no conciencia de presencia no niega el obrar constante de Dios. ¿Dónde se manifiesta ese obrar? En todas las experiencias vitales que requieren de un discernimiento que no se detiene. Para la santa antioqueña, la vida es afirmación plena del ser de Dios. No hay vida sin el ser mismo de Dios: “¿Cómo hablar de mi ser? ¿De cuál ser, si tú solo eres? ¡Si mi ser no es! (...) ¡Cómo puedo decir mi vida, si ni es vida ni es mía!" (Montoya, 2017, p. 26). La conciencia de presencia en Laura Montoya no es solo un ejercicio cognitivo de darse cuenta de algo. Se refiere a que ser consciente de la presencia es descubrir que no se es sin Dios. Así, en su proceso vital, identifica diversas etapas en las cuales esa conciencia aparece lejana o escondida.

Ahora bien, ¿qué experiencia es crucial en el proceso de conciencia de presencia en Laura Montoya? Hay un acontecimiento místico, narrado en su autobiografía, que define como una misericordia de Dios a la que denomina "experiencia del hormiguero" (Montoya, 2017, p. 41). Nos interesa tener en cuenta los principales factores que contextualizan tal experiencia. Primero, desarrolló una capacidad de observación a la naturaleza, desde niña:

Desde esta edad, es decir desde los seis años, era observadora de la naturaleza (...). Ahora me parece rara esa tendencia a observar en tan temprana edad, pero, padre mío, menos extraño debe verse si se considera que la naturaleza fue mi única amiga (...). Jugaba poco, vivía en el campo y tan sola, por dentro y por fuera, ¿qué otra cosa podría hacer? (Montoya, 2017, p. 40)

La naturaleza fue para la santa colombiana una forma de comunicarse con Dios. Precisamente, la experiencia del hormiguero se concreta en medio del campo y de lo natural. Experiencia que expresa como algo que va más allá del conocimiento cognitivo de la presencia de Dios. Es Dios mismo quien se le revela:

El medio ordinario para conocer a Dios es la enseñanza; eso no me faltó. ¿Cuántas veces Dios mío, me habían dicho que existías?, ¿cuántas veces había oído hablar de tus misericordias, en una familia cual era la mía que vivía toda endiosada? Sin embargo, no me daba cuenta de ello; por la enseñanza no entraste en mi corazón, ¡ni siquiera a mi entendimiento! Quizás había rastreado tu grandeza en el medio natural en que vivía; pero con un conocimiento tan vago, algo así como remiso, como dudoso, del cual no me daba cuenta; era como una oscuridad con algún reflejo de luz. $Y$ porque hice infructuoso el medio ordinario, apelaste al medio extraordinario. (Montoya, 2017, p. 41)

En este relato, deja claro que la conciencia de presencia que ella expresa no es solo una conciencia que surge de un ejercicio cognitivo de aprendizaje de conceptos. Tampoco de una actitud de contemplación. La conciencia de presencia tiene su valor pleno cuando el misterio mismo se revela, cuando acontece un encuentro de amor y reconocimiento.

En segundo lugar, la conciencia de presencia no es garante de una vida perfecta. Hacemos énfasis en este punto, porque, a través de su diario, expresa que aquello no es un estado abstracto, distante de la fragilidad del ser humano: "Pasada la conmoción de aquel rayo producido por ese golpe de conocimiento de Dios, volví a la casa llena del deseo de ser buena. Ojalá hubiera sido fiel a mi propósito" (Montoya, 2017, p. 42). La conciencia de presencia es, a su vez, conciencia de finitud frente a la presencia: 
Nuestro agradecimiento a Dios es tan ruin que, por fuerza, hemos de quedar vencidos y mucho es que nos dejemos querer, sin oponerle resistencia. Tantos años me he pasado trabajando por ser agradecida con Dios que, al ver mi impotencia, me le declaré vencida y determiné dejarme amar, con un abandono completo. Por eso, viendo que la lucha era tan desigual, tuve que abandonar las armas (...). Ya no pienso en luchar por corresponderle, porque la lucha supone armas iguales y ¿cuáles son las nuestras, para ponerlas en comparación con las suyas? (Montoya, 2017, p. 68).

P or último, la conciencia de presencia es una nueva forma de comunicarse con Dios. Laura Montoya define su espiritualidad como un itinerario fuera del maniquí (Montoya, 2017, p. 81): "Es sencillamente que, como mi espiritualidad se formó tan libremente y sin ellas, las miro, así como un aparato, pero muy útil" (Montoya, 2017, p. 81). Se refiere a las formas externas tradicionales de la fe. Su forma de comunicarse con el misterio pasaba por experiencias diversas y nuevas:

Tengo la costumbre de, cuando diviso cimas de cordilleras, con la imaginación me subo a ellas y, saltando de unas a otras, gozo gritando desde ellas: jViva mi Dios tan vivo!, ¡viva mi vida tan viva (...)! Otras veces llamaba a Dios a gritos en una llanura distante de la casa y le hablaba de cuanto veía. Cuando lo hacía al pie de una quebrada, le decía que sí que hacía bien esos peces (...). Con estas majaderías me ayudaba para sostener la presencia de Dios (...). Dios era mi único amigo. (Montoya, 2017, p. 56)

La oración me era habitual, pero se reducía a estar contenta, muy contenta de Dios y a saber que él era mi único (...). En todos esos dos o tres meses no tuve un ratico para Dios solo, pero como nos entendíamos, no me hacía falta. Cuando me sentía floja en alguna tarea, la estudiaba en la presencia de Dios, sintiéndome tan bien como cuando oraba. (Montoya, 2017, p. 70).

En conclusión, podemos afirmar que la conciencia de presencia en Laura Montoya es constante en la exposición de su diario. Al inicio de su autobiografía, concibió, por un lado, que es necesario preguntarse acerca del momento en el que esa conciencia de presencia acontece en su vida $y$, por otro, cómo tiene un valor significativo y constante en cada experiencia de su itinerario vital. Para ella, la conciencia de presencia es asumir que la vida no es vida sin el ser que se hace siempre presente. Presencia que moviliza nuevas formas de comunicación con el misterio. Caminos de intimidad que rompen con esquemas tradicionales para abrirse paso a un diálogo de amor auténtico.

\subsection{La contemplación en la acción de Benjamín González Buelta}

Benjamín González Buelta es un sacerdote jesuita, nacido en León, noroeste de España. Siendo muy joven, fue enviado por la Compañía de Jesús a las Antillas, donde ha permanecido más de 60 años. Estuvo durante 37 años, inicialmente, en República Dominicana; el resto del tiempo ha ejercido su ministerio en Cuba, su residencia actual. Dentro de la Compañía de Jesús, se ha desempeñado como Maestro de Novicios, en República Dominicana; Provincial de las Antillas e Instructor de la Tercera Probación en la formación de los jesuitas, en Cuba. 
Tanto su inserción en comunidades marginalizadas, asumiendo la causa de los pobres, como el ministerio de los Ejercicios Espirituales de San Ignacio de Loyola, lo han configurado como testigo de la acción del Espíritu. Como señala Fernández-Martos en la presentación de Orar en un mundo roto, "Su maestro Ignacio le fue enseñando a ser contemplativo en la acción. Así, toda la realidad se le convirtió en templo" (González Buelta, 1995, p. 11). En Bajar al encuentro de Dios explicita el aporte del carisma ignaciano: "Estas páginas están escritas dentro de la espiritualidad ignaciana. Este carisma vivo, que recibimos constantemente de Dios, nos prepara (...) para acercamos a la realidad tan compleja, al mundo real con todos sus desafíos" (González Buelta, 1995, p. 2).

Su forma de acercase a los pobres no se limita a una palabra de aliento, una enseñanza o un ejercicio de caridad, sino que, de manera más profunda, como él mismo señala, lo lleva a la búsqueda "del que quiere contemplar la presencia viva de Dios entre los que están fuera (LC 2,7), para unirnos a él, en su obra liberadora de todo mal e injusticia" (González Buelta, 1995, p. 1). Ha estado comunicando el fruto de dicha experiencia contemplativa a través de todos sus escritos, los cuales concibe como "una palabra de agradecimiento a las comunidades cristianas de los barrios marginados" (González Buelta, 2002, p. 7).

Su manera de concebir y vivir la acción del Espíritu hunde sus raíces en el misterio de la encarnación. Pues, en sus palabras, "Jesús, en su encarnación, bajó antes que nosotros a las periferias marginadas y contempló la historia desde el revés del mundo. Allí descubrió vida sorprendente que brotaba desde los descalificados y anunció la irrupción del Reino de Dios" (González Buelta, 1992, p. 7). Esta experiencia encarnatoria que caracteriza su itinerario espiritual se dinamiza desde la interacción de tres estadios: la oración contemplativa, el discernimiento y la contemplación en la acción. En sus propios términos:

En la contemplación personal se nos revela el misterio de Dios, que es siempre nuevo. En el discernimiento separamos el don original que Dios nos ofrece de cualquier escoria que nosotros le adherimos. En la contemplación en la acción percibimos la presencia de Dios, que trabaja con nosotros en la historia para crear juntos sus propuestas. (González Buelta, 2002, p. 16)

Para González Buelta, la necesidad de forjar una nueva sensibilidad para percibir a Dios y su acción en este mundo es clara y urgente, pero debe evitar, a toda costa, caer en un nuevo discurso sobre Dios, sino "ser auténticas imágenes de Dios, como su Hijo Jesús" (González Buelta, 2009, p. 8). Su experiencia personal y el itinerario espiritual del que dan cuenta sus escritos son un signo de esperanza que permite corroborar que, en medio de las crisis y los cambios de época, han emergido y siguen emergiendo "grandes místicos que han percibido a Dios de manera nueva, mucho más honda y significativa para los tiempos nuevos" (González Buelta, 1995, p. 8).

\subsubsection{La conciencia de presencia en Benjamín González Buelta}

Para González Buelta la posibilidad del encuentro con Dios no es un privilegio de una élite o un grupo determinado de personas, sino que la comprende como una dimensión de toda vida humana ("no consiste tanto en tener visiones extraordinarias como en tener una visión nueva de toda la realidad, descubriendo a Dios como su última verdad, como su 
fundamento vivo, actuante y siempre nuevo", González Buelta, 1995, p. 62). En este sentido, "todos estamos enteramente hechos para el encuentro con un tú inagotable" ("no consiste tanto en tener visiones extraordinarias como en tener una visión nueva de toda la realidad, descubriendo a Dios como su última verdad, como su fundamento vivo, actuante y siempre nuevo", González Buelta, 1995, p. 20). El acto de existir es ya expresión de esa relación con Dios, aunque no haya conciencia de ello, pues "en él vivimos, nos movemos y existimos" (Hch $17,28)$.

La creación como obra de Dios se encuentra habitada por su presencia oculta, invisible a la mirada superficial. En medio de nuestra vida, en las diferentes actividades sencillas o de mayor complejidad, "Dios nos puede sorprender haciéndonos sentir su presencia con pequeñas iluminaciones o con intensas experiencias que marcan de manera definitiva nuestra existencia" (González Buelta, 1995, p. 61-62). Lo anterior permite comprender que la posibilidad de la experiencia mística, de hacer consciente la presencia de Dios, es ante todo un don, pues es él quien toma la iniciativa de salir al encuentro.

La posibilidad de vivir tal experiencia en nuestro itinerario espiritual "no consiste tanto en tener visiones extraordinarias como en tener una visión nueva de toda la realidad, descubriendo a Dios como su última verdad, como su fundamento vivo, actuante y siempre nuevo" (González Buelta, 1995, p. 63) Por esta razón, se hace necesario liberar la mirada de todo aquello que la enceguece, la distorsiona, la condiciona y la limita; además de promover "la conversión de los sentidos para ir creando en nosotros la nueva sensibilidad evangélica" (González Buelta, 1995, p. 175). Este ejercicio incluye una disposición interior particular, como sugiere el pasaje evangélico: "Bienaventurados los limpios de corazón, porque ellos verán a Dios" (Mt 5,8).

Quien asume esa nueva visión de toda la realidad y se mueve "en el mundo con el sentimiento de una presencia" (González Buelta, 1995, p. 58), recibe el apelativo de místico de ojos abiertos. Dicho místico es, ante todo, un contemplativo que "abre bien los ojos para percibir toda la realidad, porque sabe que la última dimensión de todo lo real está habitada por Dios" (González Buelta, 1995, p. 58). Esta mirada contemplativa de la vida en toda su complejidad, su caos y sus bondades dispone para hacer consciente la presencia de Dios:

No hay personas ni situaciones donde Dios no esté y donde no pueda ser contemplado. Muchas personas han hecho itinerarios hacia los infiernos de este mundo y se han encontrado con Dios ahí con una claridad y un sabor que antes no habían experimentado en medio del éxito, las comodidades y la seguridad ante el futuro. (González Buelta, 1995, p. 41.

Esta mirada contemplativa implica mirar no solo hacia arriba o hacia la propia intimidad, sino también hacia abajo y "desde abajo al conjunto de la sociedad" (González Buelta, 1995, p. 11), pues es propio del contemplativo "buscar y hallar a Dios en todas las cosas" (González Buelta, 1995, p. 39). Esta mirada pasa, necesariamente, por un ejercicio de discernimiento, que "es una forma intensa de orar en la que tratamos de descubrir eso que el Padre sabe que nos conviene y que nosotros tenemos que descubrir" (González Buelta, 1995, p. $39)$, no al margen de la propia vida ni de la realidad, sino en una relación intensa con la 
propia persona y con la realidad, "para distinguir entre todos los impulsos interiores, cuáles son de Dios y cuáles solo parecen" (González Buelta, 1995, p. 39).

\section{Conclusiones: implicaciones de la comprensión de la categoría conciencia de presencia para la vida espiritual hoy}

En la fase final de esta reflexión centrada en la teología espiritual a partir de la experiencia mística de seis testigos de la historia, es importante ubicar dicha experiencia en el momento que vivimos: un mundo donde, según Morin, la complejidad da cuenta de una intrincada red de relaciones que hacen de la naturaleza, de la sociedad, de la política y del sujeto, un sistema organizacionista y multidimensional (Soto González, 1999). A esta comprensión se añade el punto de inflexión de una crisis mundial, o la puesta en evidencia de la absoluta fragilidad y la obsolescencia de los sistemas políticos y económicos, que observan inermes el crecimiento de los movimientos sociales, las diferencias, las brechas y el fortalecimiento de los fundamentalismos, entre otras situaciones. Surge, entonces, la siguiente pregunta: ¿qué lugar puede tener aquí la experiencia espiritual profunda?

Bajo la misma idea de complejidad es posible comprender el universo de la experiencia mística de estos testigos, que vivieron en diferentes momentos de la historia. Si bien en sus experiencias personales se identifican los rasgos comunes del fenómeno místico, como los describe Martín Velasco (2009), también es cierto que la particularidad y el matiz propio de cada experiencia está en estrecha relación con los rasgos propios de cada sujeto, su contexto familiar y su estilo de vida. Es por ello, que la experiencia mística evoca una alternativa a las dinámicas actuales del ser humano impersonal. El místico logra afirmar su individualidad asumiendo la consciencia de una Presencia que es a la vez consciencia de sí.

La apelación al carácter de individualidad, como punto inicial para la consciencia de presencia, está dirigida a las nuevas formas de individualidad del mundo moderno. La propuesta de una espiritualidad contemporánea puede proponerse desde la necesidad de autoafirmación del ser humano de hoy. El itinerario de estos seis místicos no dista de un camino de autenticidad de cara al Misterio. El proceso vital de búsqueda de la felicidad, la autorrealización de sí mismo y el culto por la autenticidad, no son ajenos al camino místico de nuestros autores. Por ende, si se quiere plantear un aporte a la espiritualidad contemporánea no se puede valorar la individualidad como un proceso negativo de la modernidad. Al contrario, puede ser un punto de diálogo frente al llamado a la experiencia mística del ser humano de este siglo.

El proceso de autoafirmación pasa por una experiencia de intimidad con el Misterio divino. Desde la perspectiva de Gregorio de Nisa, se concibe una relación de tipo esponsal del ser humano con el Amado, entendido no solamente como un ser personal sino como Misterio creador que abarca la totalidad de la creación, incluso desde la perspectiva de Ignacio de Loyola. Lo anterior también se puede encontrar en Etty Hillesum y Laura Montoya, quienes entendieron esta intimidad con la naturaleza, y el mundo. En este orden de ideas, hablamos de una conciencia de presencia que afirma la individualidad del ser 
humano siempre en una relación abierta que sale del sí mismo para entrar en relación con todo aquello que lo hace ser símismo al mismo tiempo.

Sin embargo, esta relacionalidad no se da por antonomasia. Exige un proceso del cual ninguno de los autores expuestos, estuvo exento. El reconocimiento de una consciencia de presencia vista desde el itinerario vital de los autores como proceso, establece también otra distinción para la espiritualidad contemporánea. Al contrario de lo que plantea una noción de perfeccionamiento que tienen su asidero en la técnica y la afirmación de la idea de progreso, con respecto a esta perspectiva, Gabriel Marcel afirma que en una de las problemáticas de lo religioso en el mundo contemporáneo radica en la idea de progreso. Hoy en día aquello que no puede perfeccionarse a través de la técnica es una realidad que no puede valorarse bajo las categorías de progreso; es decir, que, si algo no es susceptible de ser perfeccionado, está destinado a estancarse y a ser superado. La especialización de la técnica que puede darse constantemente en este dinamismo de perfeccionamiento, debe a su vez estar garantizada por la posibilidad de ser transmitida de unos a otros en la medida en que existe un temor de perder la posibilidad de "ir adelante" en la historia, progresar. (Marcel, 1954, pp. 15-16).

El proceso al que se refieren nuestros autores no se refiere al técnico. El proceso de la consciencia de presencia está enmarcado en una confrontación constante como lo expone Teresa de Ávila. Una confrontación que no representa un proceso de individuación lineal o en ascenso, sino que, al contrario, al estilo de Etty Hillesum y Laura Montoya se expresa en la auténtica finitud de lo humano.

La apuesta espiritual de los autores analizados es una individualidad frágil que, en la tensión entre la mirada interior y la mirada exterior, encuentra su fuerza para autoafirmarse. A diferencia de perspectivas tradicionales de la mística, la conciencia de presencia es una mirada alternativa para comprender la vigencia de lo espiritual en el mundo de hoy que presenta los procesos de individualidad como un enemigo de cualquier propuesta espiritual. Así mismo, nos permite entender que la fragilidad humana es también consciencia de una auténtica presencia que no se entiende desde patrones de perfeccionamiento de lo humano sino de apertura y diálogo a lo diverso y frágil del mundo.

Desde la mística, entendida como consciencia de presencia, se expresa la necesidad de seres humanos capaces de hacer frente a las crisis de la modernidad, desde una vulnerabilidad que los haga fuertes y sensibles a la multiplicidad de relaciones que podamos establecer como sujetos encarnados. La conciencia de presencia nos sale al encuentro, en medio de la tensión entre nuestro mundo interior y el exterior, sin perder de vista nuestra fragilidad, que se conjuga con el Misterio mismo de la divinidad que abre siempre caminos diversos de autenticidad de lo humano.

\section{Referencias Bibliográficas}

Biser, E. (1994). Pronóstico de la fe. Orientación para la época postsecularizada (C. Gancho, Trad.). Barcelona: Herder. 
Buber, M. (2017) Yo y Tú (C. Díaz Hernández, Trad.). Barcelona: Herder.

Castellano, J. (2014). Espiritualidad teresiana. Experiencia y doctrina. En A. Barrientos. (Ed.), Introducción a la lectura de Santa Teresa (pp.157-282). Madrid: De Espiritualidad.

Daniélou, J. (1944). Platonisme et théologie mystique. Doctrine spirituelle de Saint Grégoire de Nysse. París: Faculté de Théologie de Lyon.

De Dalmases, C. (1986.). El padre maestro Ignacio: breve biografía ignaciana (3a ed.). Madrid: Biblioteca de Autores Cristianos popular.

De Ávila, T. (1967). Obras completas de Santa Teresa de Jesús: edición manual (2a ed.). Madrid: Biblioteca de autores cristianos.

De Loyola, I. (1970). Ejercicios espirituales de San Ignacio de Loyola. Bilbao: Sal Terrae.

De Loyola, I. (1990). El Peregrino: autobiografía de San Ignacio de Loyola. Santander: Sal Terrae.

De Nisa, G. (1988). Homilía contra los prestamistas usureros. En C. I. Gónzalez (Ed), Pobreza y riqueza en obras selectas del cristianismo primitivo (pp. 65-93). México: Porrúa.

De Nisa, G. (2015). Homilías sobre el cantar de los cantares. En T. Martín (Ed), Semillas de contemplación, de San Gregorio de Nisa (pp. 5-196). Madrid: Biblioteca de Autores Cristianos.

Dünzl, F. (1993). Braut und Bräutigam. Die Auslegung des Canticum durch Gregor von Nyssa. Tübingen: J.C.B. Mohr.

García Ordas, Á. M. (2011). Teresa de Jesús. Presencia y experiencia (claves de interpretación) (2a ed.). Madrid: Editorial de Espiritualidad.

Goettmann, A. (1987). K.G Dürckheim. El camino, la verdad y la vida (D. García Valverde, Trad.). Madrid: Sirio.

González Buelta, B. (2009). Ver o perecer: mística de ojos abiertos (4a ed.). Santander: Sal Terrae.

González Buelta, B. (2002). Orar en un mundo roto: tiempo de transfiguración. Santander: Sal Terrae.

González Buelta, B. (1995). Bajar al encuentro de Dios. Roma: Comunidad de Vida Cristiana. https://bit.ly/3hmdnbi

González Buelta, B. (1992). Signos y parábolas para contemplar la historia: más allá de las utopías. Santander: Sal Terrae.

Hillesum, E. (2002). Etty: The letters and diaries of Etty Hillesum 1941-1943: complete and unabridged (K. Smelik, Ed.; A. J. Pomerans, Trans.). Otawa, ON: Novalis, Saint Paul University. Lenoir, F. (2003). Les métamorphoses de Dieu: la nouvelle spiritualité occidentale. Paris: Plon. 


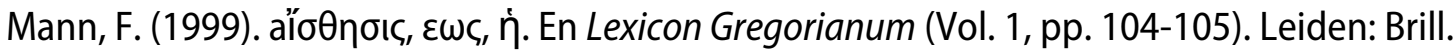

Mann F. y Drecoll, V. H. (2009). пapouøía, aç, ウ̀. En Lexicon Gregorianum (Vol. 7, pp. 179-181). Leiden: Brill.

Maraval, P. (2006). Cronología de las obras. En L. Mateo-Seco y F. Maspero (Ed). Diccionario de Gregorio de Nisa (pp. 265-284). Burgos: Monte Carmelo.

Marcel, G. (1954). Le déclin de la sagesse, Paris: Plon.

Marcos, J. A. (2015). Teresa de Jesús: la trasparencia del Misterio. Madrid: San Pablo.

Martín Velasco, J. (2009). El fenómeno místico: estudio comparado (3a ed.). Madrid: Trotta.

Melloni Ribas, J. (2001). La mistagogía de los Ejercicios. Santander: Sal Terrae.

Migne, J. P. (1863). Patrologiae cursus completus. Paris: Series Graeca.

Montoya, L. (2017). Historia de las misericordias de Dios en un alma: autobiografía Santa Laura Montoya. Bogotá: Pontificia Universidad Javeriana.

Navarro Sánchez, R. (2017). Etty Hillesum: mística y humanidad. Bogotá: Pontificia Universidad Javeriana.

Rahner, K. (1969). Escritos de Teología (Vol. 7) (J. Molina, Trad.). Madrid: Taurus.

Silvas, A. (2007). Biography. En Gregory of Nyssa: the letters (pp. 1-58). Leiden: Brill.

Soto González, M. (1999). Edgar Morin. Complejidad y sujeto humano (Tesis Doctoral). Universidad de Valladolid. https://bit.ly/3alOqFr

Taylor, C. (2008). Le malaise de la modernité (C. Melançon, Trad.). Paris: Éditions du Cerf.

Vigorelli, I. (2014). Desiderio e beatitudine: schesis nell'In Canticum Canticorum di Gregorio di Nissa. Annales Theologici, 28, pp. 277-300. https://doi.org/10.1400/227093

\section{Para citar este artículo bajo Norma APA 7a ed.}

O. Solano Pinzón, R. Navarro Sánchez, J. Gómez Díaz; W. A. Peña Esquivel y G. A. Jaramillo Vargas (2020). Gregorio de Nisa, Ignacio de Loyola, Teresa de Jesús, Laura Montoya, Etty Hillesum y Benjamín González Buelta. Cuadernos de teología - Universidad Católica del Norte (En línea), 12, e4621, https://doi.org/10.22199/issn.0719-81752020-0012

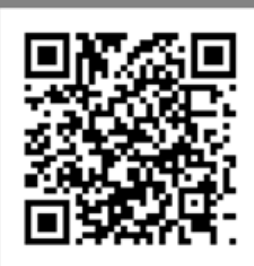

DOI

Copyright del articulo: @2020 0. OrlandoSolano, Rosana Navarro, Jairo Gómez, William Peña y G. Jaramillo

\section{(cc) BY}

Este es un artículo de acceso abierto, bajo licencia Creative Commons BY 4.0. 